\title{
The roles of RRP15 in nucleolar formation, ribosome biogenesis and checkpoint control in human cells
}

\author{
Zhixiong Dong ${ }^{1,2}$, Changjun Zhu ${ }^{1,2}$, Qimin Zhan ${ }^{3}$, Wei Jiang ${ }^{1,3}$ \\ ${ }^{1}$ Key Laboratory of Molecular and Cellular Systems Biology, Tianjin Normal University, Tianjin 300387, China \\ ${ }^{2}$ Tianjin Key Laboratory of Animal and Plant Resistance, College of Life Sciences, Tianjin Normal University, Tianjin 300387, \\ China \\ ${ }^{3}$ State Key Laboratory of Molecular Oncology, Cancer Institute and Hospital, Chinese Academy of Medical Sciences and \\ Peking Union Medical College, Beijing 100021, China \\ Correspondence to: Wei Jiang, email: wjiang6138@cicams.ac.cn \\ Changjun Zhu, email: skyzcj@mail.tjnu.edu.cn
}

Keywords: RRP15, nucleolus, ribosome biogenesis, nucleolar stress, checkpoint control

Received: June 07, 2016

Accepted: December 27, 2016

Published: January 14, 2017

\section{ABSTRACT}

The nucleolus controls ribosome biogenesis and its perturbation induces nucleolar stress that inhibits cell cycle progression and activates checkpoint responses. Here, we investigate the roles of ribosomal RNA processing protein, RRP15, in nucleolar formation, ribosome biogenesis, cell cycle progression and checkpoint control in human cells. RRP15 is localized in the nucleolus and required for nucleolar formation. In contrast to the budding yeast Rrp15p that was reported as a component of pre605 subunits, RRP15 is found in both pre-40S and pre-60S subunits and involved in regulating rRNA transcription and ribosome biogenesis. Perturbation of RRP15 induces nucleolar stress that activates RPL5/RPL11/5S rRNA (RP)-Mdm2-p53 axis checkpoint response and arrests cells at G1-G1/S in p53-proficient non-transformed RPE1 cells but not in p53-deficient HeLa and MCF7 tumor cells. Instead, p53-deficient HeLa and MCF7 cells with RRP15-dependent nucleolar stress enter S-phase with S-phase perturbation that activates ATR-Chk1- yH2AX axis DNA replication/damage checkpoint response, delaying S-G2/M progression and, ultimately, causing cell death. The selective checkpoint response, cell cycle inhibition and/or cytotoxicity induced by RRP15-dependent nucleolar stress in p53-proficient non-transformed cells and p53-deficient tumor cells suggest that RRP15 might be a potential target for cancer therapy.

\section{INTRODUCTION}

The nucleolus is a sub-organelle that controls ribosome biogenesis in all eukaryotic cells. It is not membrane bound so that the nucleolus can adopt an extremely dynamic structure with a morphology depending on the growth and physiological status of the cell $[1,2]$. Light/electronic microscopy, however, reveals that the nucleolus contains three mainly morphologically distinct regions, the fibrillar center (FC), the dense fibrillar component (DFC) and the granular component (GC) [1]. In mammalian cells, several hundred ribosomal DNA genes (rDNA repeats) separated by long intergenic spacers (IGSs) are localized in the $\mathrm{FC}$ and are responsible for $47 \mathrm{~S}$ pre-rRNA transcription [3]. 47S pre-rRNA transcription is dependent on RNA polymerase I ( $\mathrm{Pol} \mathrm{I})$. After transcription, $47 \mathrm{~S}$ pre-rRNA transcripts are located to the DFC and subjected to a series of endonucleolytic cleavages and exonucleolytic digestions, termed as prerRNA processing. Pre-rRNA processing removes internal and external transcribed spacers (ITSs and ETSs) and generates the mature 18S, 28S, and 5.8S rRNAs. These rRNAs, together with 5S rRNA transcripted by Pol III in the nucleoplasm, bind to small or large subunit ribosomal proteins (RPSs or RPLs) to assemble 40S and 60S preribosomal (pre-40S and pre-60S) subunits in GCs. Subsequently, pre-40S and pre-60S subunits are released into the nucleoplasm and then translocated through nuclear pore complex into the cytoplasm. The final rRNA processing steps occur in the cytoplasm, in which pre-40S 
and pre- $60 \mathrm{~S}$ subunits mature into $40 \mathrm{~S}$ and $60 \mathrm{~S}$ ribosome subunits that assemble into $80 \mathrm{~S}$ ribosome required for protein translation (for reviews see references [2, 4, 5]).

As ribosome biogenesis is a complex process, it is not surprising that many proteins are involved in this process. Proteomic analyses and individual studies showed that several hundred proteins were localized in the nucleolus and involved in regulating nucleolar formation, structure, function and/or ribosome biogenesis [6-8]. Upstream binding factor (UBF), a Pol I transcriptional activator and enhancer, was found in the $\mathrm{FC}$ that bound to entire regions of the rDNA repeats to regulate $47 \mathrm{~S}$ pre-rRNA transcription. Perturbation of UBF disrupted nucleolar formation and structure, resulting in a significant reduction of 47S pre-rRNA transcription and recruitment of DFC proteins, such as fibrillarin, into the nucleolus [9]. Nucleolin, an abundant nucleolar protein, was involved in regulating rDNA transcription, rRNA maturation and ribosome assembly in the nucleolus [10]. Depletion of nucleolin caused disorganization of nucleolar structure, disrupting transcription elongation of rDNA repeats and dispersing nucleolar proteins from the nucleolus into the nucleoplasm [11-13]. Ribosome proteins (30 RPSs and 49 RPLs) were crucial for assembly of pre- $40 \mathrm{~S}$ and pre-60S subunits [14]. However, despite extensive investigations, the precise functions of many nucleolar proteins, especially ribosomal RNA processing proteins (RRPs), still remain elusive.

Given the fact that ribosome biogenesis controls the protein synthesis in cells, the process is tightly linked with cell proliferation, cell cycle progression and carcinogenesis $[1,15,16]$. Large bodies of evidence indicated that perturbation of nucleolar formation/function and ribosome biogenesis could induce nucleolar stress that inhibited cell cycle progression, activated checkpoint response and promoted carcinogenesis. In mammalian cells, in response to nucleolar disruption/stress, several ribosome proteins including RPL5 and RPL11 were released from the nucleolus into the nucleoplasm where these proteins bound to $5 \mathrm{~S}$ rRNA to form RPL5/RPL11/5S rRNA complex (RP complex). The RP complex then interacted with p53-directed E3 ubiquitin ligase Mdm2 in the nucleoplasm and inhibited Mdm2 E3 ligase activity to increase $\mathrm{p} 53$ protein stability and transcriptional activity in the nucleus, thus activating p53-dependent cell cycle checkpoints [17-20]. Hence, the nucleolar stress-induced RP-Mdm2-p53 axis checkpoint responses blocked cell cycle progression and arrested cells at G1/S and/or G2/M in $\mathrm{p} 53$-proficient non-transformed cells for abnormal cell proliferation and transformation protection [12, 21-24]. Consistently, impaired activity/function of the nucleolar stress pathway could be advantageous to cancer cells as it partially alleviated surveillance of ribosome integrity by p53. Thus, like p53, RPL11 and RPL5 were found to be mutated and many ribosomal proteins were overexpressed in human cancers $[25,26]$. In addition, several recent studies also showed that perturbation of several ribosomal proteins that induced nucleolar stress in p53-deficient tumor cells could result in tumor cell death, suggesting that nucleolar stress pathway would be an attractive target for cancer therapy although the precise mechanism(s) was unclear [24, 27-29].

In this study, we investigated ribosomal RNA processing protein RRP15 involved in regulating nucleolar formation, ribosome biogenesis, cell proliferation, cell cycle progression and checkpoint control in human nontransformed and cancer cells.

\section{RESULTS}

\section{RRP15 is a nucleolar protein in human cells}

To characterize human coiled-coil proteins involved in cell cycle control, we employed a large-scale RNA interference (RNAi) screen and identified human ribosomal RNA processing protein 15 (RRP15, also called cgi115). Sequence analysis showed that ribosomal RNA processing protein 15 (Rrp15) was conserved across many species with a coiled-coil motif in the middle of the molecule (Figure 1A and Supplementary Figure 1A). We generated rabbit polyclonal anti-RRP15 antibodies ( $\alpha$-RRP15) to explore the role(s) of RRP15 in human cells. Immunoprecipitation and immunoblotting analyses revealed that $\alpha$-RRP15, but not pre-bleed sera, specifically recognized $45 \mathrm{kDa}$ RRP 15 protein (Supplementary Figure 1B).

We examined subcellular localization of endogenous RRP15 using affinity-purified $\alpha$-RRP15. Immunofluorescence showed that RRP15 was localized predominantly in the nucleolus (Figure 1B), similar to its budding yeast ortholog, Rrp15p, as previously reported [30]. RRP15 was colocalized with nucleolar proteins UBF, fibrillarin, and nucleolin in the nucleoli. To quantitate colocalization of RRP15 with these nucleolar markers, Pearson correlation coefficients ( $\mathrm{R}$ values) analysis from 30 cells for all pairwise combinations (total positive correlation appears as 1 , total negative correlation as -1 , and no correlation as 0 ) revealed that the $\mathrm{R}$ value of RRP15/UBF, RRP15/fibrillarin or RRP15/nucleolin was $0.74 \pm 0.16,0.85 \pm 0.06$ or $0.81 \pm 0.08$ (Figure 1B). Thus, these results indicated that RRP15 was a nucleolar protein in human cells.

In addition, RRP15 was detected as dispersed nucleoplasmic/cytoplasmic dots when fluorescent imaging intensities were enhanced (Supplementary Figure 2A). We coimmunostained RRP15 with endoplasmic reticulum protein, Bip (a rough ER marker), ribosome proteins RPS6 and RPL11 or $\alpha$-tubulin (cytoskeletal microtubules) to determine if RRP15 was also a ribosomal component. RRP15 was colocalized with Bip, RPS6 or RPL11 but not with $\alpha$-tubulin, suggesting that RRP15 might be also involved in ribosome function in the cytoplasm in 
human cells (Supplementary Figure 2A). Consistent with immunofluorescent results, immunoblotting analysis of subcellular nuclear and cytoplasmic fractions demonstrated that RRP15 was mainly localized in the nucleus and, to a lesser extent, in the cytoplasm (Supplementary Figure 2B).

We detected two potential nuclear localization sequences (NLS) in the N-terminus and C-terminus of RRP15 protein (Figure 1A, red boxes). Analysis of a nucleolar localization sequence (NoLS) detector (http:// www.compbio.dundee.ac.uk/www-nod) suggested that the NLS in the C-terminus of RRP15 might be responsible for RRP15 nucleolar localization. To determine if the N-terminal and/or C-terminal NLS of RRP15 were required for RRP15 protein nuclear and/or nucleolar localization, we generated a set of RRP15 mutant proteins fused with green fluorescent protein (GFP) and expressed these proteins (GFP-tagged RRP15 proteins) in HeLa cells using mammalian expression vectors (Figure 1C). Fluorescence imaging and Pearson correlation coefficients of these mutants with nucleolin ( $\mathrm{R}$ values) were determined. As shown in Figure $1 \mathrm{D}$, deletion of the C-terminus (N150), but not the N-terminus (C175), of RRP15 resulted in perturbation of RRP15 nucleolar localization. Furthermore, deletion of the C-terminal NLS alone ( $\Delta 228-232)$ could sufficiently abrogate RRP15 nucleolar localization (Figure 1D). Taken together, these results indicated that the C-terminal NLS of RRP15 was a functional NoLS required for RRP15 nucleolar localization. In contrast, the N-terminal NLS of RRP15 was only functioned as a NLS, together with the C-terminal NLS of RRP15, required for RRP15 nuclear localization.

\section{RRP15 is required for nucleolar formation}

Subcellular localization of RRP15 suggested that RRP15 could play roles in nucleolar function and/or ribosome biogenesis in human cells. To determine RRP15 functions, we ablated RRP15 in HeLa cells using specific RRP15 small interfering RNAs (siRNAs). Transfection of chemically synthesized RRP15-targeted siRNA (RRP15 siRNA) or endonuclease-prepared RRP15-targeted siRNA (RRP15 esiRNA), but not control siRNA or mock (buffer), significantly reduced endogenous mRNA and protein levels of RRP15 (Figure 2A and Supplementary Figure 3).
A
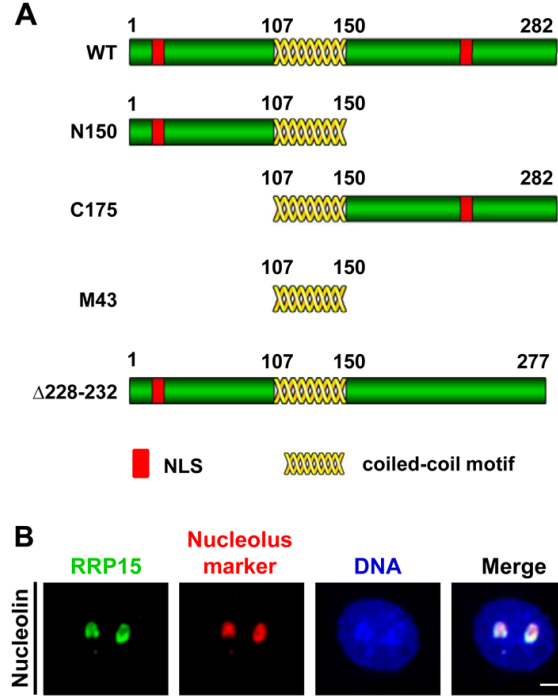

Nucleolus
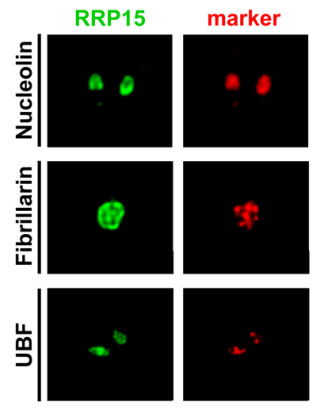
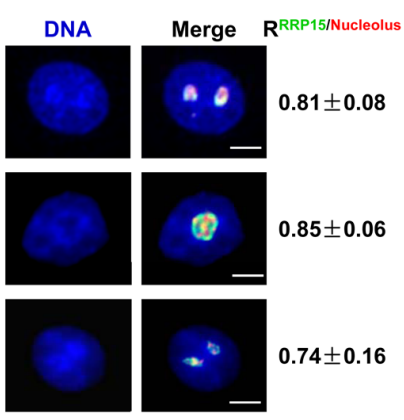
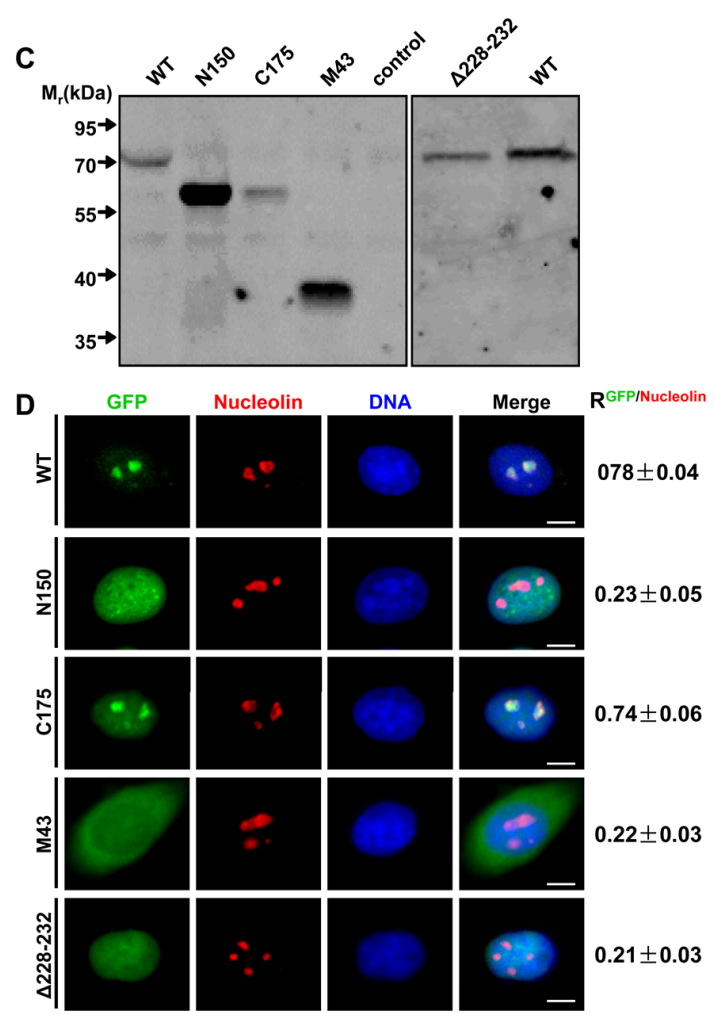

Figure 1: Subcellular localization of RRP15. A. The schematic diagrams of RRP15 wild type (WT) and different mutants. B. Immunofluorescence analysis of HeLa cells with rabbit $\alpha$-RRP15 and mouse $\alpha$-nucleolin, $\alpha$-fibrillarin or $\alpha$-UBF. DNA was visualized by DAPI staining. $R$ values were obtained as described (see supplementary Materials and Methods). Scale bars, $5 \mu \mathrm{m}$. C. HeLa cells were

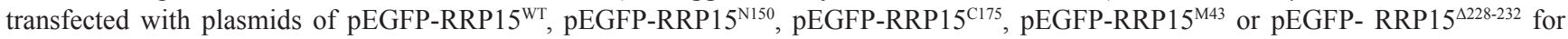
48 h. Cell lysates were immunoblotted with mouse $\alpha$-GFP. D. HeLa cells grown on coverslips were transfected with plasmids of $\mathrm{pEGFP-}$ RRP15 ${ }^{\mathrm{wT}}$, pEGFP-RRP15 ${ }^{\mathrm{N} 150}$, pEGFP-RRP15 $5^{\mathrm{C} 175}$, pEGFP-RRP15 $5^{\mathrm{M} 43}$ or pEGFP- RRP15 $5^{\Delta 228-232}$ for 48 h. The cells were fixed and stained with mouse $\alpha$-nucleolin and DAPI. Scale bars, $5 \mu \mathrm{m}$. R values were obtained as described in (B). 
Immunofluorescence and fluorescence intensities of nucleolar marker nucleolin, fibrillarin or UBF in control cells or cells depleted of RRP15 were determined. As shown in Figure 2B-2D, in contrast to control cells, cells depleted of RRP15 displayed drastic perturbation of nucleolar formation with nucleolin, fibrillarin and UBF dispersing into the nucleoplasm. Consistently, cells depleted of RRP15 also perturbed nucleolar localization of RPL11 and RPS6 that resulted in RPL11 and RPS6 to disperse into the nucleoplasm (Supplementary Figure 4A-4B). However, depletion of RRP15 had little effect on the cytoplasmic localization of RPS6 and RPL11 in these cells (Supplementary Figure 4A-4B). These results indicated that RRP15 was involved in regulating nucleolar formation.

If RRP15 is critical for nucleolar formation, expression of exogenous RRP15, but not its NoLS deletion mutant $(\Delta 228-232)$, would reestablish the nucleolus in RRP15-depleted cells. Hence, we performed knockdown-rescue experiments, in which HeLa cells were cotransfected with RRP15 esiRNA that targeted the 3'UTR of RRP15 mRNA together with mammalian expression vector expressing GFP-tagged RRP15 or GFP-tagged RRP15 ${ }^{\Delta 228-232}$ using RRP15 cDNA coding region without the 3'UTR. Immunoblotting and immunofluorescence analyses showed that RRP15 esiRNA could effectively ablate the expression of endogenous RRP15 but not the expression of exogenous GFP-tagged RRP15 or GFPtagged RRP15 ${ }^{\Delta 228-232}$ (Supplementary Figure 5A). Cells expressing GFP-tagged RRP15, but not GFP-tagged RRP15 ${ }^{\Delta 228-232}$, restored nucleolar formation with nucleolin localizing in the nucleolus (Supplementary Figure 5B-5C). Taken together, these results demonstrated that RRP15 was not only a protein localized in the nucleolus but also a protein required for nucleolar formation in human cells.

\section{RRP15 is constitutes of pre-40S and pre-60S ribosomal subunits and participates in ribosome biogenesis}

The crucial role of RRP15 in nucleolar formation promoted us to investigate the nucleolar function(s) of RRP15. As one of the primary nucleolar functions in eukaryotic cells was to assemble pre-ribosomal subunits, we examined if RRP15 was involved in assembling pre$40 \mathrm{~S}$ and/or pre-60S ribosomal subunits in human cells. To this end, we fractionized HeLa cell nuclear extracts to obtain pre-40S and pre-60S ribosomal subunits fractions using a sucrose gradient by ultracentrifugation as previously described [31]. As shown in Figure 3A, analysis of the sucrose gradient fractions by specphotometer revealed that pre-40S ribosomal subunits presented mainly in the fractions 5 and 6 whereas pre$60 \mathrm{~S}$ ribosomal subunits presented mainly in the fractions 9 and 10. Immunoblotting analysis of proteins from each sucrose gradient fraction showed that RRP15 presented predominantly in 5, 6, 9 and 10 fractions, indicating that
A
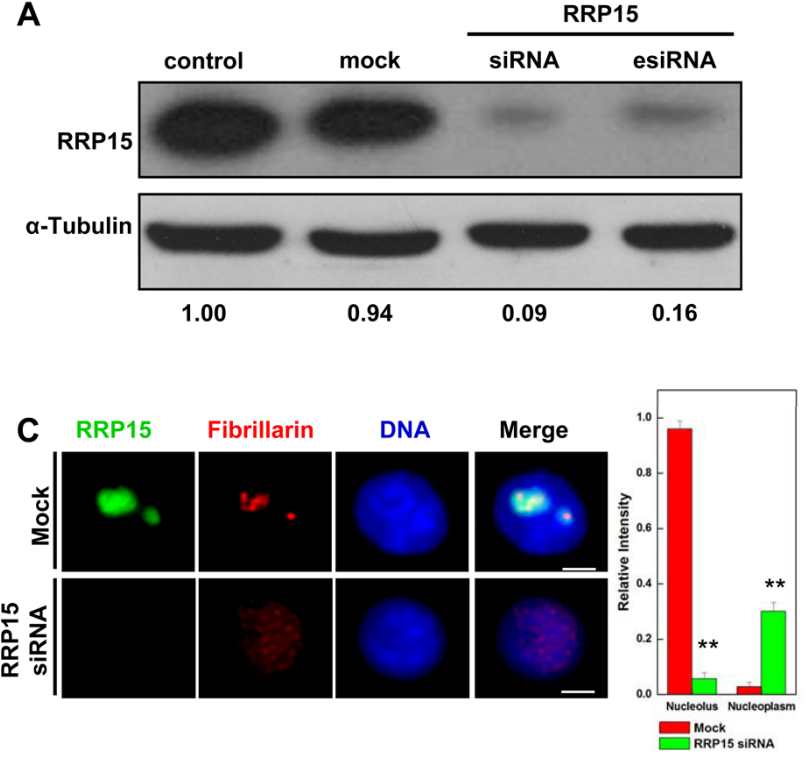
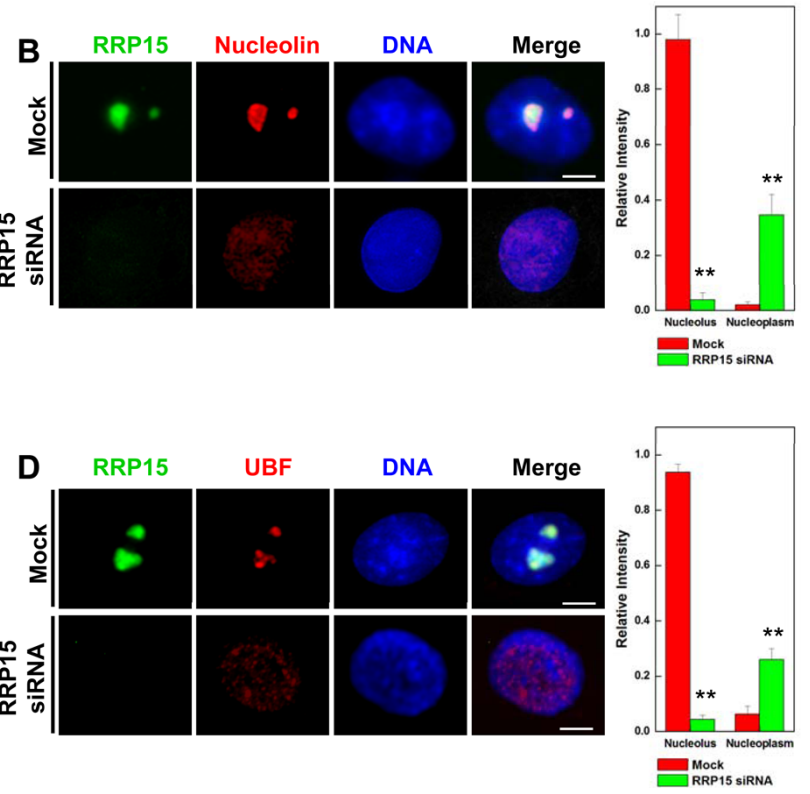

Figure 2: Nucleolar formation and nucleolin, fibrillarin and UBF localization in cells depleted RRP15. A. HeLa cells were transfected with mock (buffer), control siRNA, RRP15 siRNA or RRP15 esiRNA for $48 \mathrm{~h}$ and cell lysates were immunoblotted with $\alpha$-RRP15 and anti- $\alpha$-Tubulin antibody. B-D. HeLa cells grown on coverslips were transfected with or without RRP15 siRNA for 48 h, fixed and immunostained with $\alpha$-RRP15 and $\alpha$-nucleolin, $\alpha$-fibrillarin or $\alpha$-UBF. DNA was visualized by DAPI staining. Scale bars, $5 \mu$ m. Intensities of nucleolin, fibrillarin or UBF staining in the nucleoli and the nucleoplasm in 20 cells were determined by Image-Pro Plus 7.0. $* * \mathrm{P}<0.01$. 
RRP15 was not only a constitute of pre-60S ribosomal subunits as previous studies reported for budding yeast Rrp15p [32], but also a constitute of pre-40S ribosomal subunits in human cells (Figure 3B).

To determine if RRP15 participated in ribosome biogenesis, we ablated expression of RRP15 by RRP15 siRNA and analyzed assembly of pre-40S, pre-60S, 40S, $60 \mathrm{~S}$ or $80 \mathrm{~S}$ ribosomal subunits and polysomes in cells depleted of RRP15. As shown in Figure 3C, sucrose gradient analysis indicated that, when compared to control, ablation of RRP15 resulted in significant reductions of pre-40S and pre-60S ribosomal subunits in HeLa cells, similar to the results obtained from HeLa cells treated with actinomycin D (ActD), a RNA polymerase I inhibitor that blocked transcription of 47S pre-rRNA from rDNA repeats and thus affected assembly of pre-40S and pre-60S ribosomal subunits [33]. Furthermore, ablation of RRP15 also resulted in decreased $40 \mathrm{~S}, 60 \mathrm{~S}, 80 \mathrm{~S}$ and polysomes in cells depleted of RRP15 when compared with control cells (Supplementary Figure 6A). Consistent with these results, immunoblotting analysis revealed that when compared with control cells, protein synthesis profile of GAPDH was significantly decreased in cells depleted of RRP15, similar to cells treated with cycloheximide (CHX) for $8 \mathrm{~h}$
(Supplementary Figure 6B and 6C). Taken together, these results indicated that RRP15 was involved in regulating in ribosome biogenesis in human cells.

\section{RRP15 is involved in rRNA transcription}

In eukaryotic cells, ribosome biogenesis was initiated from $47 \mathrm{~S}$ pre-rRNA transcription at rDNA repeats in the nucleolus. Subsequently, a series of rRNA processing was executed by exonuclease and endonuclease. The processed rRNAs together with the rRNA associated proteins then assembled into pre-40S and pre-60S ribosomal subunits (Supplementary Figure 7A and $[1,5,9])$. rRNA transcription at rDNA repeats and rRNA processing were considered as the critical rate-limiting steps for ribosome biogenesis in the nucleolus [34]. As RRP15 was required for nucleolar formation and ribosome biogenesis (Figure 1-3), we examined if, besides its role(s) in rRNA processing [35], RRP15 might also participate in regulating rRNA transcription. To this end, we made a pair of specific primers that amplified 5'-ETS of 47S prerRNA to monitor $47 \mathrm{~S}$ pre-rRNA transcription using realtime reverse transcription-polymerase chain reaction (RTPCR) (Figure 4A). Total RNA isolated from control cells,
A

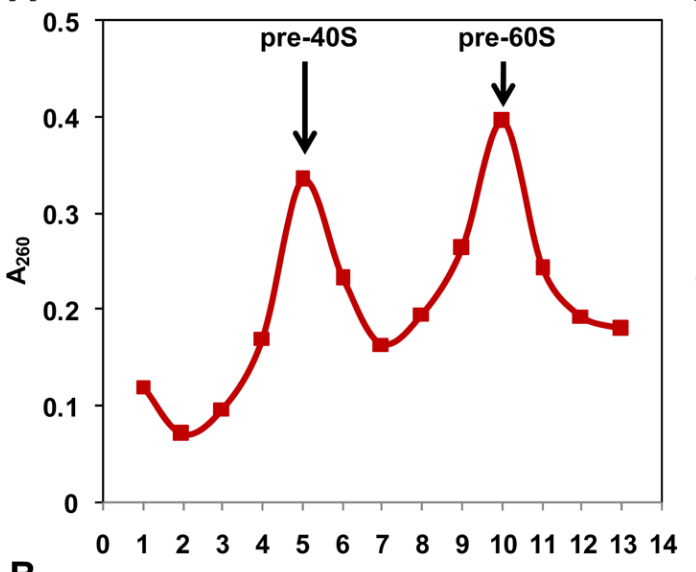

C

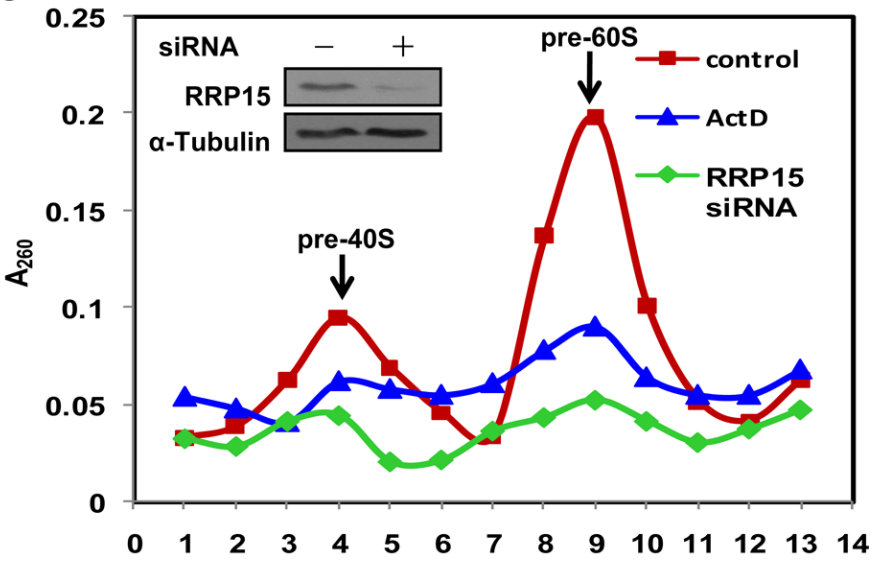

B

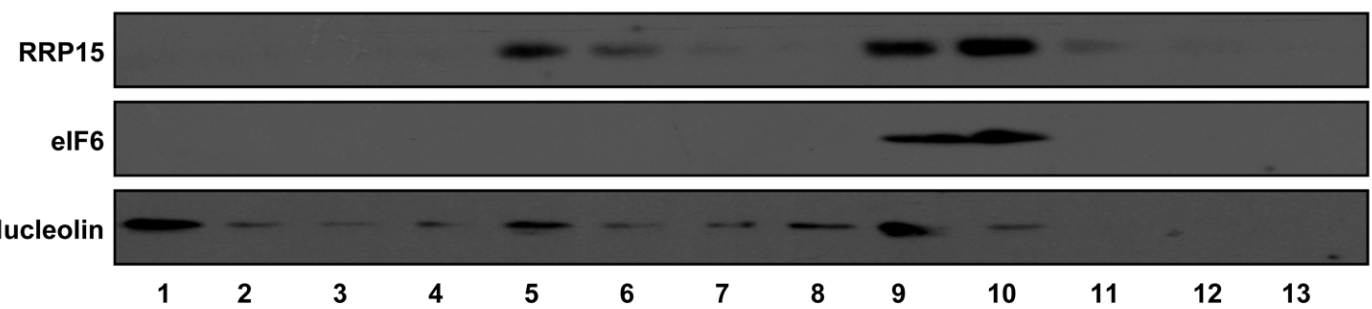

Figure 3: Presentation and regulation of RRP15 in pre-40S and pre-60S ribosomal subunits and ribosome biogenesis. A. Pre-ribosomal profile in HeLa cells. Nuclear extracts were prepared from HeLa cells and fractionized on $10 \%$ to $40 \%$ sucrose density gradient. The absorbance at $260 \mathrm{~nm}\left(\mathrm{~A}_{260}\right)$ of each fraction was profiled and the positions of pre-ribosomal subunits were indicated. B. RRP15 in pre-ribosomal subunits. Proteins from fractions described in (A) were separated on a SDS-PAGE and immunoblotted with $\alpha$-RRP15, $\alpha$-eIF6 (pre-60S ribosomal subunit protein) and $\alpha$-Nucleolin (nucleolar protein). C. Ribosome biogenesis impaired by RRP15 depletion. HeLa cells transfected with or without RRP15 siRNA for $48 \mathrm{~h}$ or HeLa cells were treated with ActD for $12 \mathrm{~h}$ (positive control) were collected. Pre-ribosomal subunits were purified from these cells and profiled as described in (A). RRP15 depletion was determined by immunoblotting analysis (insert). 
cells depleted of RRP15 or cells treated with ActD, was subjected to real-time RT-PCR amplification. The results showed that, in contrast to control cells, cells depleted of RRP15 displayed significant inhibition of 47S pre-rRNA synthesis whereas cells treated with ActD showed a drastic block of 47S pre-rRNA synthesis, indicating that RRP15 was involved in regulating rRNA transcription (Figure 4A).

To characterize the regulation of RRP15 on rRNA transcription in detail, we performed chromatin crosslinking and immunoprecipitation (ChIP) assays in HeLa cells. Cells were cross-linked with formaldehyde and cell lysates were then immunoprecipitated by $\alpha$-RRP15 or $\alpha$-UBF. DNA enrichment in the $\alpha$-RRP15 or $\alpha-U B F-$ immunoprecipitates was amplified by PCR using sets of DNA primers spanning through the entire human rDNA repeats with a resolution of $\sim 0.5-1 \mathrm{~kb}$ (Figure $4 \mathrm{~B}-4 \mathrm{C}$ and [36]). ChIP analysis indicated that UBF bound to the entire rDNA repeats as previously reported whereas RRP15 only interacted with the transcription initiation region ( $\mathrm{H} 1$ and $\mathrm{H} 4)$ and the long intergenic spacers (IGS) (H18, H27 and H32) of the rDNA repeats (Figure 4B-4C) [13, 37]. As RRP15 was a ribosomal RNA processing protein, it was possibly that interaction of
A

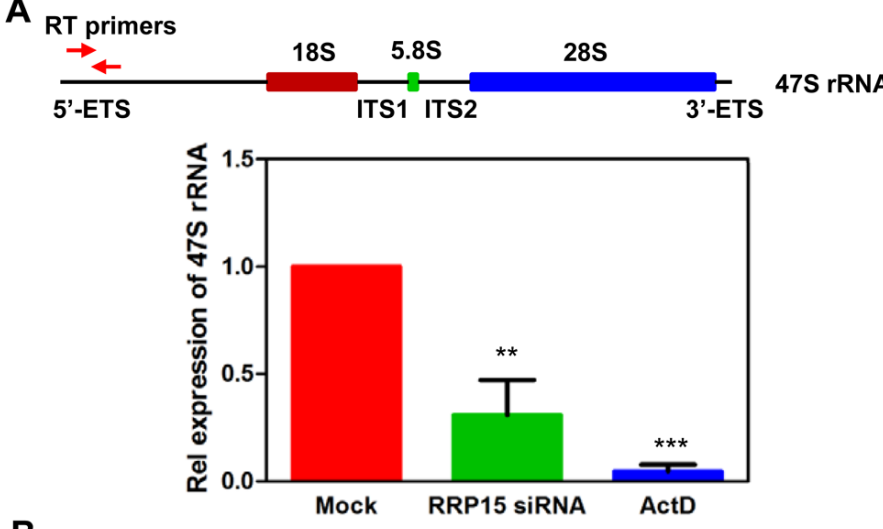

B

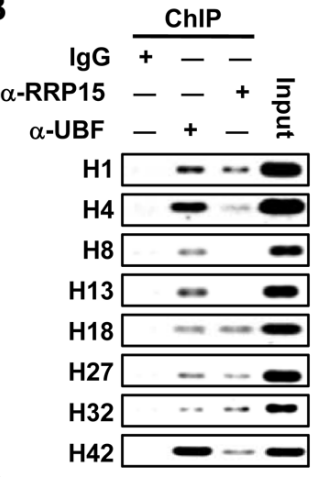

C

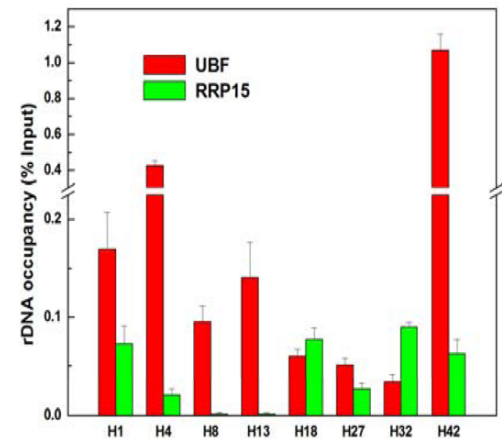

D
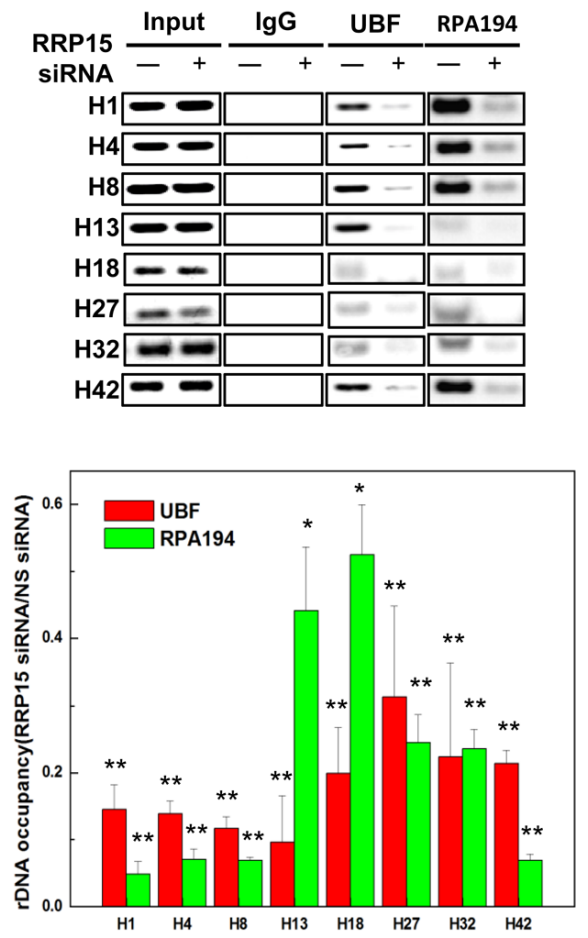

Transcription

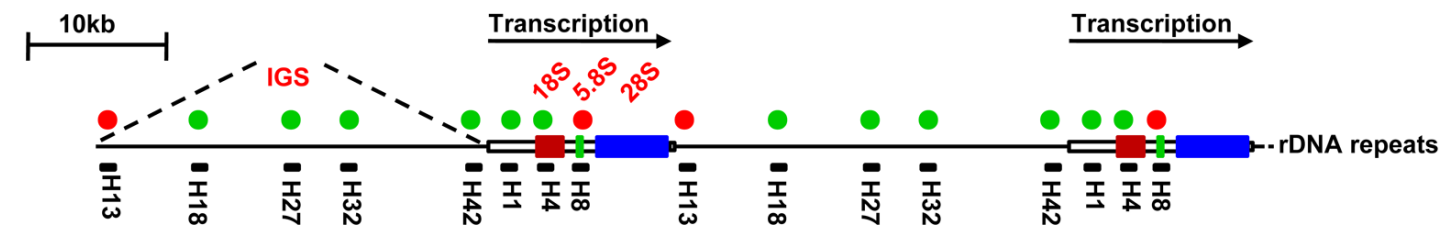

Figure 4: Regulation of 47S pre-rRNA transcription by RRP15. A. The effects of RRP15 on 47S pre-rRNA transcription. Total RNA from HeLa cells transfected with or without RRP15 siRNA for $48 \mathrm{~h}$ or treated with ActD for $12 \mathrm{~h}$ (positive control) was extracted and $47 \mathrm{~S}$ pre-rRNA was amplified by real-time RT-PCR using specific primers as indicated in the diagram of 47S pre-rRNA. Histograms represented 47S pre-rRNA levels in HeLa cells treated with control, RRP15 siRNA and ActD. B. Determination of RRP15 binding sites in rDNA loci by ChIP analysis. HeLa cells were cross-linked and immunoprecipitated by IgG (negative control), $\alpha$-UBF (positive control) or $\alpha$-RRP15. DNA in IgG, $\alpha$-UBF or $\alpha$-RRP15 immunoprecipitates was amplified by indicated PCR primers and then separated by agrose gel electrophoresis. Histograms represented the percentages of DNA immunoprecipitated by $\alpha$-RRP 15 and $\alpha$-UBF that were relative to input DNA. C. A schematic representation of human rDNA repeats with RRP15 binding sites. Green circle dots represented RRP15 binding sites and red circle dots represented RRP15 negative binding sites. Primer pairs (black solid bars) and their approximate positions relative to the transcription start are indicated. D. Perturbation of UBF and RPA194 association with rDNA loci by RRP15 depletion. HeLa cells transfected with or without RRP15 siRNA for $48 \mathrm{~h}$ were employed to perform ChIP analysis described in (B) using $\alpha$-UBF and $\alpha$-RPA194. Histograms represented the percentages of DNA immunoprecipitated by $\alpha$-UBF and $\alpha$-RPA194 that were relative to input DNA in cells transfected with or without RRP15 siRNA. ${ }^{*} \mathrm{P}<0.05$ and $* * \mathrm{P}<0.01$. 
RRP15 with rDNA repeats was mediated by pre-rRNA. To determine this, we pre-treated formaldehyde crosslinked cell lysates with RNase I and then the lysates were immunoprecipitated by $\alpha$-RRP15. ChIP analysis revealed that association of RRP15 with rDNA repeats was not affected by RNase I treatment, indicating that association of RRP15 with rDNA repeats was not mediated by prerRNA (Supplementary Figure 8).

To further determine how RRP15 binding to rDNA repeats affected rRNA transcription, we examined the possibility that RRP15 influenced Pol I transcriptional machinery. Despite many attempts, we were unable to detect RRP15 co-immunoprecipitation with UBF (negative data not shown). However, when we monitored UBF and RPA194 (a subunit of Pol I) with rDNA repeats in control cells or cells depleted of RRP15, we found that, in contrast to control cells, cells depleted of RRP15 displayed significantly decreased association UBF and RPA194 with rDNA repeats (Figure 4D). These results suggested that RRP15 binding to rDNA repeats participated in the regulation of rRNA transcription by affecting association of transcription machinery with
rDNA repeats, perhaps by facilitating Pol I recruitment and/ or stabilization on rDNA repeats.

\section{Regulation of cell proliferation and cell cycle progression by RRP15-dependent nucleolar formation/ribosome biogenesis in various human cells}

Given the fact that nucleolar formation/ribosome biogenesis is tightly linked with cell proliferation, cell cycle progression and checkpoint control $[1,15,16]$, we next determined the effects of RRP15-dependent nucleolar formation/ribosome biogenesis on cell proliferation and cell cycle progression in human cells. Expression of RRP15 was ablated by RRP15 siRNA in non-transformed cell line, RPE1, and cancerous cell lines, HeLa or MCF7 (Supplementary Figure 9A). Cell proliferation analysis (MTT assay, see Materials and Methods) revealed that depletion of RRP15 in RPE1, HeLa or MCF7 cells resulted in inhibition of cell proliferation as compared with controls (Figure 5A). However, while non-transformed
A
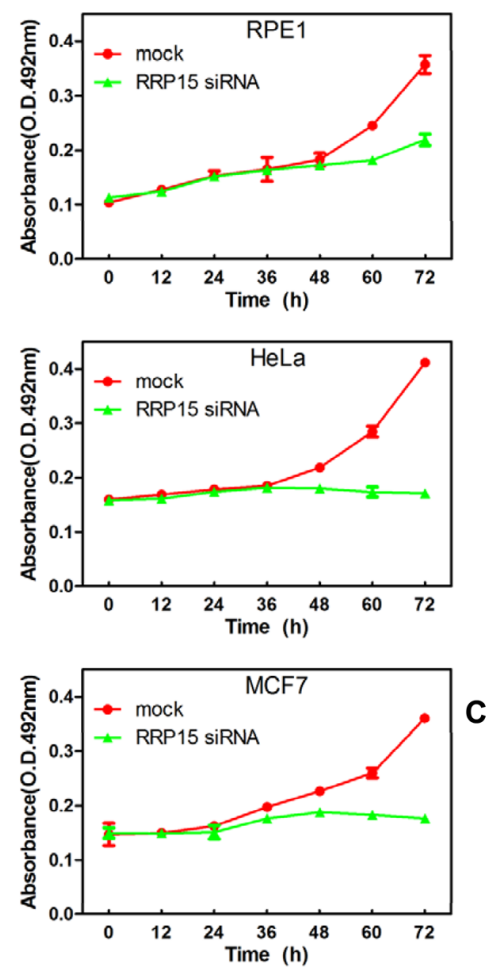

B

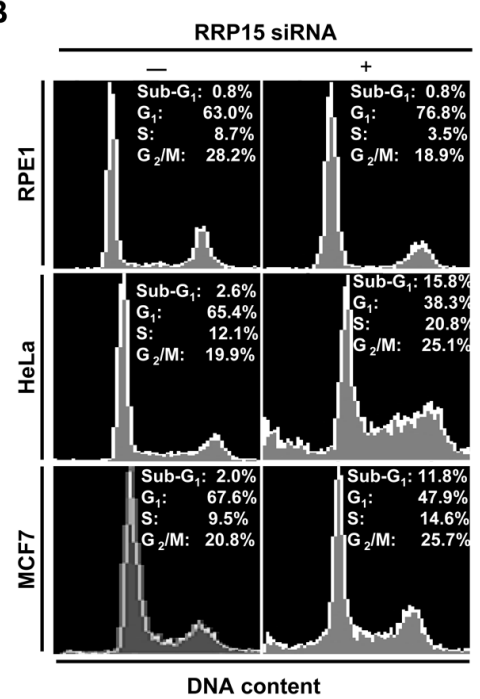

C

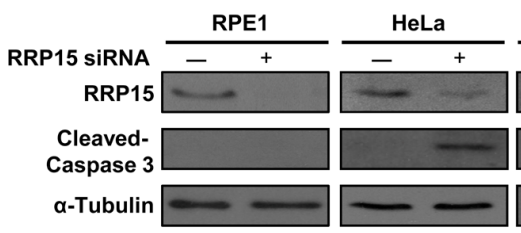

D
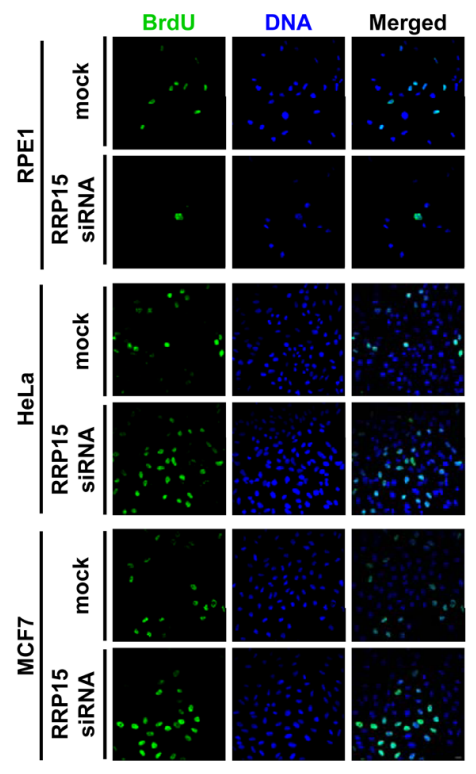

Figure 5: The effects of RRP15 ablation on cell proliferation and cell cycle progression in various human cells. A. Inhibition of cell proliferation by RRP15 depletion in various human cells. RPE1 (up), HeLa (middle) and MCF7 cells (low) were transfected with or without RRP15 siRNA and cell proliferation was determined by MTT assay at indicated times. Results represent means \pm standard deviations of five independent experiments. B. RPE1 (up), HeLa (middle) and MCF7 cells (low) were transfected with or without RRP15 siRNA for $48 \mathrm{~h}$ and cell cycle profiles were monitored by flow cytometry. Results are representative of three independent experiments. C. RPE1, HeLa and MCF7 cells were transfected with or without RRP15 siRNA for $48 \mathrm{~h}$. The cell lysates were immunoblotted with $\alpha$-RRP15, $\alpha$-Caspase 3 and anti- $\alpha$-Tubulin antibody. D. The effects of RRP15 depletion on BrdU (5-bromo-2'-deoxyuridine) incorporation in various human cells. Cells transfected with or without RRP15 siRNA for $48 \mathrm{~h}$ were labeled with $10 \mathrm{mM}$ BrdU (1 h). The cells were fixed and immunostained with mouse $\alpha$-BrdU. DNA was visualized by DAPI staining. 
RPE1 cells depleted of RRP15 exhibited a 55\% decrease in proliferation rate, cancerous HeLa or MCF7 cells depleted of RRP15 displayed complete inhibition of cell proliferation. Fluorescent-Activated Cell Sorting (FACS) analysis showed that, when compared with controls, depletion of RRP15 in RPE1 cells resulted in an increased accumulation of cells in G1 to G1/S phase whereas depletion of RRP15 in HeLa or MCF7 cells caused an accumulation of cells in $\mathrm{S}$ to $\mathrm{G} 2 / \mathrm{M}$ phase (Figure $5 \mathrm{~B}$ and Supplementary Figure 9B). In addition, depletion of RRP15 in HeLa or MCF7 cells also resulted in a marked accumulation of sub-G1 phase (cell death). Consistently, immunofluorescence or immunoblotting analysis showed that depletion of RRP15 in HeLa or MCF7 cells, but not RPE1 cells, induced apoptotic markers annexin V positive cell staining and the cleaved caspase 3 fragment (Figure 5C and Supplementary Figure 9C). Restoration of GFP-RRP15, but not GFP-RRP15 ${ }^{\Delta 228-232}$, expression in HeLa cells depleted of RRP15 reduced annexin V positive cell staining (Supplementary Figure 5A and 9D). We monitored that depletion of RRP15 in HeLa or MCF7 cells caused cell death directly by time-lapse microscopy. In contrast to control cells that progressed through cell cycle and divided into two daughter cells normally (Supplementary Figure 10 dotted arrows and Supplementary Movie 1 and Movie 3), HeLa or MCF7 cells depleted of RRP15 displayed delayed cell cycle progression, ultimately undergoing cell death (Supplementary Figure 10 solid arrows and Supplementary Movie 2 and Movie 4).

We investigated how depletion of RRP15 resulted in G1-G1/S arrest in non-transformed RPE1 cells and $\mathrm{S}-\mathrm{G} 2 / \mathrm{M}$ phase block and cell death in cancerous HeLa or MCF7 cells. To this end, we monitored S-phase by BrdU incorporation in RPE1, HeLa or MCF7 cells treated with control or RRP15 siRNA. As shown in Figure 5D and Supplementary Figure 9E, when compared with controls, depletion of RRP15 expression in RPE1 cells resulted in significant reduction of BrdU incorporation whereas depletion of RRP15 in HeLa and MCF7 cells resulted in accumulation of BrdU incorporation. These results indicated that depletion of RRP15 in non-transformed RPE1 cells arrested cells in G1-G1/S phase and blocked S-phase entry. In contrast, depletion of RRP15 in cancerous HeLa or MCF7 cells did not inhibit cell cycle progression at G1-G1/S phase, resulting in that these cells entered S-phase, and, ultimately, caused cell death.

\section{RRP15 ablation induces nucleolar stress response in p53-proficient RPE1 cells but $S$-phase checkpoint response in p53-deficient HeLa or MCF7 cells}

We determined the mechanism(s) by which depletion of RRP15 resulted in G1-G1/S phase arrest in
RPE1 cells, and S-G2/M phase arrest and cell death in HeLa or MCF7 cells. Since depletion of RRP15 perturbed nucleolar formation/ribosome biogenesis, we reasoned that depletion of RRP15 in non-transformed p53-proficient RPE1 cells would activate RP-Mdm2-p53 axis nucleolar stress checkpoint response by dispersing RPL11 from the nucleolus into the nucleoplasm, increasing RPL11 interaction with $\mathrm{Mdm} 2$ and resulting in accumulation of p53 that arrested cells at G1-G1/S phase. Consistent with the speculation, immunoprecipitation and immunoblotting analyses showed that depletion of RRP15 in RPE1 cells caused significantly increased interaction of RPL11 with Mdm2 and accumulations of p53 and p53 downstream target, CDK inhibitor p21, when compared with controls (Figure 6A and 6B). In contrast, expression of cell cycle regulators, CDK2 and Cyclin D1, was not significantly altered in RPE1 cells depleted of RRP15 (Figure 6B). These results indicated that perturbation of RRP15dependent nucleolar formation/ribosome biogenesis by RRP15 depletion activated RP-Mdm2-p53 axis nucleolar stress checkpoint response, thereby blocking nontransformed p53-proficient RPE1 cells at G1-G1/S phase.

However, as p53 function was defective in cancerous HeLa or MCF7 cells due to E6 oncoprotein expression in $\mathrm{HeLa}$ cells or $\mathrm{Mdm} 2$ oncoprotein overexpression in MCF7 cells [38-40], we found that, in contrast to RPE1 cells, depletion of RRP15 did not result in accumulations of p53 and p21 in p53-deficient HeLa or MCF7 cells (Figure 6C), although depletion of RRP15 perturbed nucleolar formation and induced nucleolar localized RPL11 dispersing from the nucleolus into the nucleoplasm in HeLa cells (Supplementary Figure 4A). Thus, RP-Mdm2-p53 axis nucleolar stress checkpoint response was not effectively activated in HeLa and MCF7 cells depleted of RRP15, resulting in that these cells entered S-phase (Figure 5B). However, as perturbation of RRP15-dependent nucleolar formation/ ribosome biogenesis could affect protein synthesis (Figure 3 and Supplementary Figure 6A-6C) that might be required for further cell cycle progression (i.e. DNA replication), we speculated that these effects on HeLa or MCF7 cells depleted of RRP15 might activate ATM/ATRChk1/2- $\gamma \mathrm{H} 2 \mathrm{AX}$ axis DNA replication/damage checkpoint response in S-phase, delaying S-G2/M phase progression and ultimately causing cell death. To test the possibility, we examined DNA replication/damage checkpoint response in control and RRP15-depleted RPE1, HeLa or MCF7 cells. Immunoblotting analysis showed that depletion of RRP15 in HeLa or MCF7 cells, but not RPE1 cells, resulted in increased levels of phosphorylated ATR and Chk1, indicating that ATR/Chk1 DNA replication/ damage checkpoint response was activated in HeLa or MCF7 cells depleted of RRP15 when compared with controls (Figure 6D and Supplementary Figure 11A). In addition, when compared with RPE1 cells, HeLa or MCF7 
cells depleted of RRP15 also displayed significantly increased levels of ATR/Chk1 downstream target, $\gamma \mathrm{H} 2 \mathrm{AX}$ (phosphorylated $\mathrm{H} 2 \mathrm{AX}$ ) by immunoblotting analysis and $\gamma \mathrm{H} 2 \mathrm{AX}$ foci formation by immunofluorescence analysis (Figure 6E-6G). Inhibition of ATR/Chk1 DNA replication/ damage checkpoint response in cells depleted of RRP15 by treatment of caffeine, a nonspecific inhibitor of PIKK, abrogated $\gamma \mathrm{H} 2 \mathrm{AX}$ induction (Supplementary Figure 11B-11D). Thus, these results, together with data obtained from FACS analysis and time-lapse microscopy (Figure 5B and Supplementary Figure 9 and 10), demonstrated that, in contrast to non-transformed p53-proficient RPE1 cells, perturbation of RRP15-dependent nucleolar formation/ribosome biogenesis by RRP15 depletion in p53-deficient HeLa or MCF7 cells did not effectively activate RP-Mdm2-p53 axis nucleolar stress checkpoint response to block cells at G1-G1/S. Instead, p53-deficient HeLa or MCF7 cells depleted of RRP15 entered S-phase with S-phase perturbation, activating ATR-Chk1- $\gamma \mathrm{H} 2 \mathrm{AX}$ axis DNA replication/damage checkpoint response that delayed S-G2/M phase progression and, ultimately, caused cell death.

\section{DISCUSSION}

We investigated the functions of ribosomal RNA processing protein, RRP15, in human cells. Our results demonstrated that RRP15 was a nucleolar protein required for nucleolar formation. RRP15 participated in not only ribosome biogenesis but also rRNA transcription. Perturbation of RRP15-dependent nucleolar formation/ ribosome biogenesis induced RP-Mdm2-p53 axis nucleolar
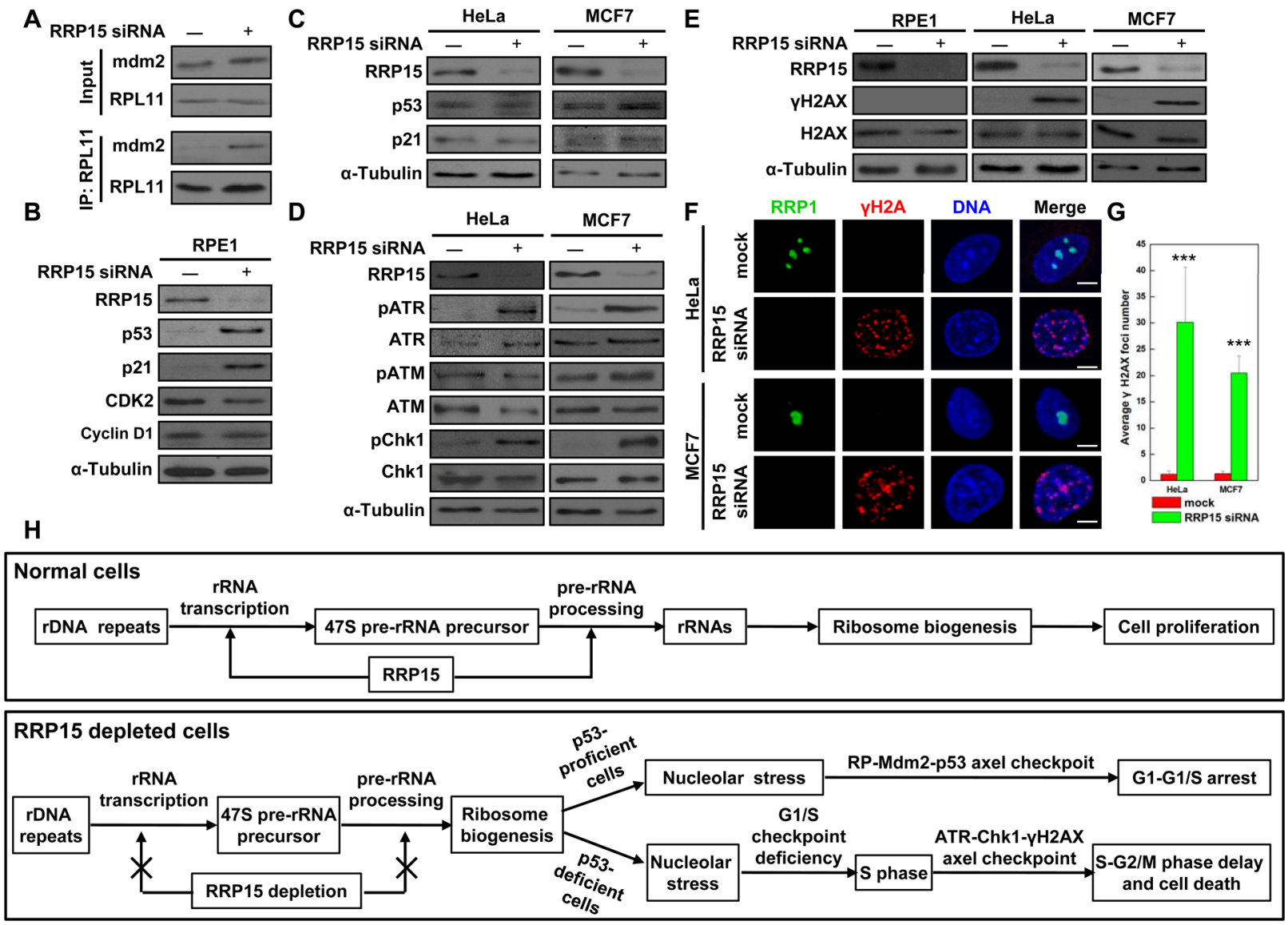

Figure 6: Induction of nucleolar stress response in p53-proficient RPE1 cells or S-phase checkpoint response in p53deficient HeLa or MCF7 cells by RRP15 ablation. A. RRP15 depletion in RPE1 cells enhanced Mdm2 interaction with RPL11. RPE1 cells were transfected with or without RRP15 siRNA for $48 \mathrm{~h}$. Whole-cell lysates were subjected to immunoprecipitation and immunoblotting analyses. B and C. The effects of RRP15 depletion on expression of cell cycle related proteins in various human cells. RPE1, HeLa or MCF7 cells were transfected with or without RRP15 siRNA for $48 \mathrm{~h}$. Whole cell lysates were immunoblotted with indicated antibodies. D. The effects of RRP15 depletion on the expression of DNA damage related proteins in various human cells. HeLa or MCF7 cells were transfected with or without RRP15 siRNA for $48 \mathrm{~h}$. Whole cell lysates were immunoblotted with indicated antibodies. E and F. RRP15 depletion induced increases of $\gamma \mathrm{H} 2 \mathrm{AX}$ level and $\gamma \mathrm{H} 2 \mathrm{AX}$ foci formation in HeLa and MCF7 cells. RPE1, HeLa or MCF7 cells transfected with or without RRP15 siRNA for $48 \mathrm{~h}$ were immunoblotted or immunostained with indicated antibodies. Scale bars, $5 \mu \mathrm{m}$. G. Histograms represented average numbers of $\gamma \mathrm{H} 2 \mathrm{AX}$ foci detected in 20 cells in $(\mathrm{F}) .{ }^{*} * \mathrm{P}<0.001$. H. The model of RRP15 involved in regulating ribosome biogenesis and cell proliferation (for detail, see text). 
stress checkpoint response and arrested cells at G1-G1/S in p53-proficient non-transformed RPE1 cells but activated ATR-Chk1- $\gamma \mathrm{H} 2 \mathrm{AX}$ axis DNA replication/damage checkpoint response and caused S-G2/M block and, ultimately, cell death in p53-deficient HeLa or MCF7 cells.

Previous studies showed that the budding yeast Rrp15p, a component of pre-60S subunits, was required for rRNA processing of 27SA2 at the C2 cleavage site and was involved in regulating the maturation of pre$60 \mathrm{~S}$ ribosomal subunit [32]. Although depletion of Rrp15p inhibited cell proliferation, large-scale affinity purification analyses by mass-spectrometry did not define the precise maturation stage(s) of the pre-ribosomal particles containing Rrp15p. Recently, based on the nucleolar proteomics obtained from various organisms, Lionel Tafforeau et al. selected 625 candidates localized at the nucleolus and examined these proteins involved in pre-rRNA processing and ribosome biogenesis. They found that RRP15 was involved in regulating the maturation of pre-40S and pre-60S rRNA intermediates. Depletion of RRP15 resulted in accumulation of $41 \mathrm{~S}$ rRNA intermediate and reductions of $21 \mathrm{~S}$ and $12 \mathrm{~S}$ rRNA intermediates, indicating that RRP15 was required for early pre-rRNA processing steps that was critical for both pre-40S and pre-60S ribosome biogenesis [35]. Consistent with these findings, our results revealed that RRP15 was components of both pre-40S and pre-60S subunits, thus indicating that RRP15 participated in the control of pre$40 \mathrm{~S}$ and pre-60S ribosome biogenesis.

Several studies demonstrated that rDNA active transcription played a crucial role for nucleolar formation $[41,42]$. As RRP15 was required for nucleolar formation, depletion of RRP15 inhibited 47S pre-rRNA transcription and reduced association of Pol I with rDNA repeats. These results, together with the role of RRP15 in prerRNA processing [35], suggested that RRP15 could be a multifunctional factor involved in regulating ribosome biogenesis at different stages (Supplementary Figure 7B). Nucleolar proteins, such as nucleolin and nucleophosmin, were shown to have multiple roles in regulating ribosome biogenesis at different stages. Nucleolin, a histone chaperone with a FACT-like (FAcilitates Chromatin Transcription) activity, was involved in not only rRNA transcription but also rRNA processing and ribosomal assembly. Depletion of nucleolin perturbed nucleolar organization, inhibited rRNA transcription by affecting chromatin remodeling and histone dynamics and blocked early steps of rRNA processing in the 5' ETS [11-13, 43]. Nucleophosmin was involved in regulating rRNA transcription by recruiting the transcriptional factor c-Myc to rDNA repeats [44]. However, nucleophosmin also functioned as an endoribonuclease whose activity played an important role in pre-rRNA processing in the ITS2 [45]. Hence, as a coiled-coil protein, RRP15 could interact with crucial nucleolar proteins to assemble multiple complexes required for regulating rRNA transcription and/or rRNA processing/ribosomal assembly in the nucleolus (Figure $6 \mathrm{H})$. NOP16, a potential RRP15 associated protein identified by bioinformatic studies, was reported to have important roles in governing rRNA transcription and regulating ribosome assembly [46].

A mounting body of evidence demonstrated that perturbations of nucleolar function/ribosome biogenesis generated nucleolar stress that inhibited cell cycle progression and activated the canonical RP-Mdm2-p53 axis checkpoint response for abnormal cell growth and transformation protection [12, 21, 24, 47]. Consistent with these studies, our results showed that perturbation of RRP15-dependent nucleolar formation and ribosome biogenesis that induced nucleolar stress activated RPMdm2-p53 axis checkpoint response and arrested cells at G1-G1/S in p53-proficient non-transformed cells. However, our results further revealed that RRP15dependent nucleolar stress could not activate RPMdm2-p53 axis checkpoint response and arrest cells at G1-G1/S in p53-deficient tumor cells. Instead, these p53deficient tumor cells with RRP15-dependent nucleolar stress entered S-phase with S-phase perturbation, activating ATR-Chk1- $\gamma \mathrm{H} 2 \mathrm{AX}$ axis DNA replication/ damage checkpoint response that delayed S-G2/M phase progression and ultimately caused cell death (Figure $6 \mathrm{H})$. Perturbation of nucleolar formation and ribosome biogenesis by depletion/mutation of critical nucleolar proteins and/or treatment with RNA transcription inhibitor ActD was reported to cause cell death in p53deficient tumor cells [24, 27-29, 48]. In addition, previous studies demonstrated that varieties of endo- and/or extracellular stresses could affect nucleolar formation and/or ribosome biogenesis, which, in turn, turn on nucleolarstress dependent checkpoint responses. For instance, in response of DNA damage (UV, IR or chemotherapy drug treatment), reactive oxygen species (ROS) induction or nutrient deprivation, nucleolar formation and/or function would be impaired, resulting in abnormalities of nucleolar formation/function that would stabilize p53 and induce nucleolar-stress dependent checkpoint responses [21, 4951]. It could be possible that nucleolar stress checkpoint response and other cell cycle checkpoint responses including DNA damage checkpoint response could sever as a regulatory control loop(s) to monitor cell cycle progression in eukaryotic cells.

In summary, we investigated ribosomal RNA processing protein RRP15 involved in regulating nucleolar formation, ribosome biogenesis, cell proliferation, cell cycle progression and checkpoint control in human non-transformed and cancer cells. Our study provides new insights into how perturbation of RRP15-dependent nucleolar formation/ribosome biogenesis caused cell death in p53-deficient tumor cells. Thus, the selective checkpoint response, cell cycle inhibition and cytotoxicity induced by RRP15-dependent nucleolar stress in p53-proficient non-transformed cells 
and p53-deficient tumor cells suggest that RRP15 might be a potential target for cancer therapy.

\section{MATERIALS AND METHODS}

\section{Cell culture, transfection and drug treatment}

Human cervical carcinomas HeLa cells, human breast adenocarcinoma MCF7 cells and RPE1 (hTERTRPE1) cells were purchased from ATCC. The validation of the identity of HeLa, MCF7 and RPE1 cells was determined by Tianjin Weikai Bioeng LTD (China, Tianjin). HeLa and MCF7 cells were cultured in DMEM (HyClone) supplemented with $10 \%$ fetal bovine serum (FBS) (HyClone). RPE1 cells were cultured in DMEM: F-12 (1:1) (HyClone) containing 10\% FBS. All cells were cultured at $37^{\circ} \mathrm{C}$ in $5 \% \mathrm{CO}_{2}$. Plasmid/siRNA transfection was conducted with Lipofectamine 3000 and/ or RNAiMAX Reagent (Life Technologies Inc) according to manufacturer's protocol. In brief, HeLa, MCF7 and RPE1 cells were plated in 96-well plates (3000 cells/ well), 24 -well plates $\left(2 \times 10^{4}\right.$ cells/well) or 6 -well plates $\left(1 \times 10^{5} \mathrm{cells} /\right.$ well $)$ for $16 \mathrm{~h}$ at $37^{\circ} \mathrm{C}$ before transfection. Then, cells were incubated with indicated plasmids/ siRNAs plus transfection reagent mixture in medium for $24 \mathrm{~h}$ and then changed into fresh medium. Cycloheximide (CHX) (Aladdin) and Actinomycin D (ActD) (Byotime) were used for cell treatment at final concentration of 10 $\mu \mathrm{M} \mathrm{CHX}$ and $5 \mathrm{nM} \mathrm{ActD}$ at indicated times as previously described [52].

\section{Preribosome and polysome preparation}

Nuclear extracts were fractionated and preribosome preparation was performed as described previously [31] with minor modifications. In brief, HeLa cells were swollen in ice-cold hypotonic lysis buffer $(10$ $\mathrm{mM}$ Tris [pH 7.4], $10 \mathrm{mM} \mathrm{KCl}, 2 \mathrm{mM} \mathrm{MgCl}_{2}, 0.05 \%$ Triton X-100, $1 \mathrm{mM}$ EGTA, $1 \mathrm{mM}$ DTT, $40 \mathrm{mg} / \mathrm{ml}$ of phenylmethylsulfonyl fluoride, and $10 \mathrm{mg} / \mathrm{ml}$ of protease inhibitor cocktail). The nuclei pellet was collected by centrifugation at $500 \mathrm{~g}$ for $5 \mathrm{~min}$. The nuclear lysate was extracted in extraction buffer $(25 \mathrm{mM}$ Tris $(\mathrm{pH} 7.5)$, $100 \mathrm{mM} \mathrm{KCl}, 1 \mathrm{mM}$ DTT, $2 \mathrm{mM}$ EDTA, 0.1\% NP-40, $1 \mathrm{mM} \mathrm{NaF}, 40 \mathrm{mg} / \mathrm{ml}$ of phenylmethylsulfonyl fluoride, $10 \mathrm{mg} / \mathrm{ml}$ of protease inhibitor cocktail and $0.1 \mathrm{U} / \mathrm{ml}$ of RNasin (Promega)) and sonicated. The nuclear lysate was overlaid on 10 to $30 \%(\mathrm{wt} / \mathrm{wt}$ ) sucrose gradients in preribosome buffer ( $25 \mathrm{mM}$ Tris $(\mathrm{pH} 7.5), 100 \mathrm{mM}$ $\mathrm{KCl}, 1 \mathrm{mM}$ DTT and $2 \mathrm{mM}$ EDTA) and centrifuged at $36,000 \mathrm{rpm}$ for $3 \mathrm{~h}$ at $4^{\circ} \mathrm{C}$ in a Beckman SW41Ti rotor. The gradients were collected downward and the absorbance of each fraction was measured at $260 \mathrm{~nm}$ using a spectrophotometer.

Polysome preparation was performed as described previously [31] with minor modifications. In brief, HeLa cells were collected and suspended in lysis buffer $(20 \mathrm{mM}$
Tris- $\mathrm{HCl}$ [pH 7.4], $130 \mathrm{mM} \mathrm{KCl,} 10 \mathrm{mM} \mathrm{MgCl} 2,2.5 \mathrm{mM}$ dithiothreitol, $0.5 \% \mathrm{NP}-40,0.5 \%$ sodium deoxycholate, $10 \mu \mathrm{g} / \mathrm{ml} \mathrm{CHX,} 0.2 \mathrm{mg} / \mathrm{ml}$ heparin and 200U/ml RNase inhibitor) and incubated on ice for $15 \mathrm{~min}$. Lysates were centrifuged at 8,000g for $15 \mathrm{~min}$ and supernatants were collected. Supernatants were layered over 10 to $45 \%$ (wt/ wt) sucrose density gradients in polysome buffer $(10 \mathrm{mM}$ Tris- $\mathrm{HCl}$ [pH 7.4], $60 \mathrm{mM} \mathrm{KCl}, 10 \mathrm{mM} \mathrm{MgCl} 2,1 \mathrm{mM}$ dithiothreitol and $0.1 \mathrm{mg} / \mathrm{ml}$ heparin) and centrifuged at $36,000 \mathrm{rpm}$ for $3 \mathrm{~h}$ at $4^{\circ} \mathrm{C}$ in a Beckman SW41Ti rotor. The gradients were collected downward and the absorbance of each fraction was measured at $260 \mathrm{~nm}$ using a spectrophotometer.

\section{Chromatin cross-linking and immunoprecipitation (ChIP)}

ChIP analysis was performed using the ChIP Assay Kit (upstate) according to manufacturer's protocol. The chromatin solution was immunoprecipitated with indicated antibodies. The immunoprecipitates were amplified by PCR using sets of DNA primers spanning through the entire human rDNA repeats with a resolution of $\sim 0.5$ $1 \mathrm{~kb}$ as described previously [36]. PCR products were separated by agrose gel electrophoresis and densitometries of electrophoretic bands were quantitated by using Scion Image software.

\section{Cell proliferation (MTT) assay, cell cycle analysis and BrdU incorporation assay}

For cell proliferation (MTT) assay, HeLa, MCF7 or RPE1 cells were plated in 96-well plates (3000 cells/ well) for $16 \mathrm{~h}$. Cells were then transfected with or without RRP15 siRNA using RNAiMAX Transfection Reagent for $24 \mathrm{~h}$. After transfection, cells were changed into fresh medium and determined by MTT (3-(4,5-dimethylthiazol2-yl)-2,5-diphenyltetrazolium bromide) analysis at indicated times as described previously [53].

For cell cycle analysis, HeLa, MCF7 or RPE1 were fixed in $70 \%$ ethanol $/ 30 \%$ phosphate-buffered saline (PBS) for $1 \mathrm{~h}$ at $-20^{\circ} \mathrm{C}$. After fixation, cells were washed once with PBS, resuspended, and incubated in propidium iodide (PI) buffer $(60 \mu \mathrm{g} / \mathrm{ml} \mathrm{PI}$ and $0.1 \mathrm{mg} /$ $\mathrm{ml}$ RNase A) for $45 \mathrm{~min}$ at room temperature. Flow cytometry was conducted on at least 5,000 cells per condition using a FACSort and CellQuest version 3.3 (BD Biosciences). Cell cycle profiles were processed and analyzed using FlowJo version 6.4.7 (Tree Star, Ashland, OR).

BrdU incorporation was performed as described previously [23]. Cells were fixed and immunostained with mouse $\alpha$-BrdU. The percentages of BrdU positive cells were scored (>1000 cells) using a fluorescence microscope.

Extended materials and experimental procedures can be found in Supplementary Materials and Methods. 


\section{ACKNOWLEDGMENTS}

We thank Orrin L. Jiang for critical reading of the manuscript and Shuangshuang Liang for technical supports.

\section{CONFLICTS OF INTEREST}

The authors declare no conflicts of interest.

\section{FUNDING}

This work was supported by the National Basic Research Program of China (2012CB910703 to WJ), National Natural Science Foundation of China (81572685 to WJ, 31271485 to $\mathrm{CZ}$ and 31301138 to ZD), Tianjin Research Program of Application Foundation and Advanced Technology (12JC2DJC21400 to CZ and 14JCYBJC24200 to ZD), and Program for New Century Excellent Talents in University in China (NCET-11-1066 to CZ).

\section{REFERENCES}

1. Boisvert FM, van Koningsbruggen S, Navascues J, Lamond AI. The multifunctional nucleolus. Nat Rev Mol Cell Biol. 2007; 8:574-585.

2. Orsolic I, Jurada D, Pullen N, Oren M, Eliopoulos AG, Volarevic S. The relationship between the nucleolus and cancer: Current evidence and emerging paradigms. Semin Cancer Biol. 2015.

3. Smirnov E, Cmarko D, Mazel T, Hornacek M, Raska I. Nucleolar DNA: the host and the guests. Histochem Cell Biol. 2016; 145:359-372.

4. de la Cruz J, Karbstein K, Woolford JL, Jr. Functions of ribosomal proteins in assembly of eukaryotic ribosomes in vivo. Annu Rev Biochem. 2015; 84:93-129.

5. Nerurkar P, Altvater M, Gerhardy S, Schutz S, Fischer U, Weirich C, Panse VG. Eukaryotic Ribosome Assembly and Nuclear Export. Int Rev Cell Mol Biol. 2015; 319:107-140.

6. Andersen JS, Lyon CE, Fox AH, Leung AK, Lam YW, Steen H, Mann M, Lamond AI. Directed proteomic analysis of the human nucleolus. Curr Biol. 2002; 12:1-11.

7. Scherl A, Coute Y, Deon C, Calle A, Kindbeiter K, Sanchez JC, Greco A, Hochstrasser D, Diaz JJ. Functional proteomic analysis of human nucleolus. Mol Biol Cell. 2002; 13:4100-4109.

8. Andersen JS, Lam YW, Leung AK, Ong SE, Lyon CE, Lamond AI, Mann M. Nucleolar proteome dynamics. Nature. 2005; 433:77-83.

9. McCann KL, Baserga SJ. Driving nucleolar assembly. Genes Dev. 2014; 28:211-213.

10. Tajrishi MM, Tuteja R, Tuteja N. Nucleolin: The most abundant multifunctional phosphoprotein of nucleolus. Commun Integr Biol. 2011; 4:267-275.
11. Ma N, Matsunaga S, Takata H, Ono-Maniwa R, Uchiyama $\mathrm{S}$, Fukui K. Nucleolin functions in nucleolus formation and chromosome congression. J Cell Sci. 2007; 120:2091-2105.

12. Ugrinova I, Monier K, Ivaldi C, Thiry M, Storck S, Mongelard F, Bouvet P. Inactivation of nucleolin leads to nucleolar disruption, cell cycle arrest and defects in centrosome duplication. BMC Mol Biol. 2007; 8:66.

13. Cong R, Das S, Ugrinova I, Kumar S, Mongelard F, Wong $\mathrm{J}$, Bouvet P. Interaction of nucleolin with ribosomal RNA genes and its role in RNA polymerase I transcription. Nucleic Acids Res. 2012; 40:9441-9454.

14. Panse VG, Johnson AW. Maturation of eukaryotic ribosomes: acquisition of functionality. Trends Biochem Sci. 2010; 35:260-266.

15. Zhang $\mathrm{Y}, \mathrm{Lu} \mathrm{H}$. Signaling to $\mathrm{p} 53$ : ribosomal proteins find their way. Cancer Cell. 2009; 16:369-377.

16. Boulon S, Westman BJ, Hutten S, Boisvert FM, Lamond AI. The nucleolus under stress. Mol Cell. 2010; 40:216-227.

17. Michael D, Oren M. The p53-Mdm2 module and the ubiquitin system. Semin Cancer Biol. 2003; 13:49-58.

18. Zhang Y, Wolf GW, Bhat K, Jin A, Allio T, Burkhart WA, Xiong Y. Ribosomal protein $\mathrm{L} 11$ negatively regulates oncoprotein MDM2 and mediates a p53-dependent ribosomal-stress checkpoint pathway. Mol Cell Biol. 2003; 23:8902-8912.

19. Bursac S, Brdovcak MC, Pfannkuchen M, Orsolic I, Golomb L, Zhu Y, Katz C, Daftuar L, Grabusic K, Vukelic I, Filic V, Oren M, Prives C, Volarevic S. Mutual protection of ribosomal proteins L5 and L11 from degradation is essential for p53 activation upon ribosomal biogenesis stress. Proc Natl Acad Sci U S A. 2012; 109:20467-20472.

20. Donati G, Peddigari S, Mercer CA, Thomas G. 5S ribosomal RNA is an essential component of a nascent ribosomal precursor complex that regulates the Hdm2-p53 checkpoint. Cell Rep. 2013; 4:87-98.

21. Rubbi CP, Milner J. Disruption of the nucleolus mediates stabilization of p53 in response to DNA damage and other stresses. EMBO J. 2003; 22:6068-6077.

22. Sun XX, Dai MS, Lu H. 5-fluorouracil activation of p53 involves an MDM2-ribosomal protein interaction. J Biol Chem. 2007; 282:8052-8059.

23. Lau E, Chiang GG, Abraham RT, Jiang W. Divergent S phase checkpoint activation arising from prereplicative complex deficiency controls cell survival. Mol Biol Cell. 2009; 20:3953-3964.

24. Yu W, Qiu Z, Gao N, Wang L, Cui H, Qian Y, Jiang L, Luo J, Yi Z, Lu H, Li D, Liu M. PAK1IP1, a ribosomal stressinduced nucleolar protein, regulates cell proliferation via the p53-MDM2 loop. Nucleic Acids Res. 2011; 39:2234-2248.

25. Shenoy N, Kessel R, Bhagat TD, Bhattacharyya S, Yu $\mathrm{Y}$, McMahon C, Verma A. Alterations in the ribosomal machinery in cancer and hematologic disorders. J Hematol Oncol. 2012; 5:32. 
26. Goudarzi KM, Lindstrom MS. Role of ribosomal protein mutations in tumor development (Review). Int $\mathbf{J}$ Oncol. 2016; 48:1313-1324.

27. Itahana $\mathrm{K}$, Bhat KP, Jin A, Itahana Y, Hawke D, Kobayashi R, Zhang Y. Tumor suppressor ARF degrades B23, a nucleolar protein involved in ribosome biogenesis and cell proliferation. Mol Cell. 2003; 12:1151-1164.

28. Ma H, Pederson T. The nucleolus stress response is coupled to an ATR-Chk1-mediated G2 arrest. Mol Biol Cell. 2013; 24:1334-1342.

29. Hamdane N, Herdman C, Mars JC, Stefanovsky V, Tremblay MG, Moss T. Depletion of the cisplatin targeted HMGB-box factor UBF selectively induces p53-independent apoptotic death in transformed cells. Oncotarget. 2015; 6:2751927536. doi: 10.18632/oncotarget.4823.

30. Huh WK, Falvo JV, Gerke LC, Carroll AS, Howson RW, Weissman JS, O'Shea EK. Global analysis of protein localization in budding yeast. Nature. 2003; 425:686-691.

31. Strezoska Z, Pestov DG, Lau LF. Bop1 is a mouse WD40 repeat nucleolar protein involved in $28 \mathrm{~S}$ and 5. 8S RRNA processing and 60S ribosome biogenesis. Mol Cell Biol. 2000; 20:5516-5528.

32. De Marchis ML, Giorgi A, Schinina ME, Bozzoni I, Fatica A. Rrp15p, a novel component of pre-ribosomal particles required for $60 \mathrm{~S}$ ribosome subunit maturation. RNA. 2005; 11:495-502.

33. Scala F, Brighenti E, Govoni M, Imbrogno E, Fornari F, Trere D, Montanaro L, Derenzini M. Direct relationship between the level of p53 stabilization induced by rRNA synthesis-inhibiting drugs and the cell ribosome biogenesis rate. Oncogene. 2016; 35:977-989.

34. Chedin S, Laferte A, Hoang T, Lafontaine DL, Riva $\mathrm{M}$, Carles C. Is ribosome synthesis controlled by pol I transcription? Cell Cycle. 2007; 6:11-15.

35. Tafforeau L, Zorbas C, Langhendries JL, Mullineux ST, Stamatopoulou V, Mullier R, Wacheul L, Lafontaine DL. The complexity of human ribosome biogenesis revealed by systematic nucleolar screening of Pre-rRNA processing factors. Mol Cell. 2013; 51:539-551.

36. Grandori C, Gomez-Roman N, Felton-Edkins ZA, Ngouenet C, Galloway DA, Eisenman RN, White RJ. c-Myc binds to human ribosomal DNA and stimulates transcription of rRNA genes by RNA polymerase I. Nat Cell Biol. 2005; 7:311-318.

37. O'Sullivan AC, Sullivan GJ, McStay B. UBF binding in vivo is not restricted to regulatory sequences within the vertebrate ribosomal DNA repeat. Mol Cell Biol. 2002; 22:657-668.

38. Scheffner M, Werness BA, Huibregtse JM, Levine AJ, Howley PM. The E6 oncoprotein encoded by human papillomavirus types 16 and 18 promotes the degradation of p53. Cell. 1990; 63:1129-1136.

39. Werness BA, Levine AJ, Howley PM. Association of human papillomavirus types 16 and 18 E6 proteins with p53. Science. 1990; 248:76-79.
40. Sheikh MS, Shao ZM, Hussain A, Fontana JA. The p53binding protein MDM2 gene is differentially expressed in human breast carcinoma. Cancer Res. 1993; 53:3226-3228.

41. Hisaoka M, Ueshima S, Murano K, Nagata K, Okuwaki M. Regulation of nucleolar chromatin by B23/nucleophosmin jointly depends upon its RNA binding activity and transcription factor UBF. Mol Cell Biol. 2010; 30:4952-4964.

42. Grob A, Colleran C, McStay B. Construction of synthetic nucleoli in human cells reveals how a major functional nuclear domain is formed and propagated through cell division. Genes Dev. 2014; 28:220-230.

43. Ginisty H, Amalric F, Bouvet P. Nucleolin functions in the first step of ribosomal RNA processing. EMBO J. 1998; 17:1476-1486.

44. Li Z, Hann SR. Nucleophosmin is essential for c-Myc nucleolar localization and c-Myc-mediated rDNA transcription. Oncogene. 2012.

45. Savkur RS, Olson MO. Preferential cleavage in preribosomal RNA byprotein B23 endoribonuclease. Nucleic Acids Res. 1998; 26:4508-4515.

46. Kundel DW, Stromquist E, Greene AL, Zhdankin O, Regal RR, Rose-Hellekant TA. Molecular characterizations of Nop16 in murine mammary tumors with varying levels of c-Myc. Transgenic Res. 2012; 21:393-406.

47. Fumagalli S, Ivanenkov VV, Teng $\mathrm{T}$, Thomas G. Suprainduction of p53 by disruption of $40 \mathrm{~S}$ and $60 \mathrm{~S}$ ribosome biogenesis leads to the activation of a novel G2/M checkpoint. Genes Dev. 2012; 26:1028-1040.

48. Montanaro L, Mazzini G, Barbieri S, Vici M, NardiPantoli A, Govoni M, Donati G, Trere D, Derenzini M. Different effects of ribosome biogenesis inhibition on cell proliferation in retinoblastoma protein- and p53-deficient and proficient human osteosarcoma cell lines. Cell Prolif. 2007; 40:532-549.

49. Kazyken D, Kaz Y, Kiyan V, Zhylkibayev AA, Chen CH, Agarwal NK, Sarbassov dos D. The nuclear import of ribosomal proteins is regulated by mTOR. Oncotarget. 2014; 5:9577-9593. doi: 10.18632/oncotarget.2473.

50. Adamczyk J, Deregowska A, Skoneczny M, Skoneczna A, Kwiatkowska A, Potocki L, Rawska E, Pabian S, Kaplan J, Lewinska A, Wnuk M. Adaptive response to chronic mild ethanol stress involves ROS, sirtuins and changes in chromosome dosage in wine yeasts. Oncotarget. 2016; 7:29958-29976. doi: 10.18632/oncotarget.8673.

51. Larsen DH, Stucki M. Nucleolar responses to DNA doublestrand breaks. Nucleic Acids Res. 2016; 44:538-544.

52. Goudarzi KM, Nister M, Lindstrom MS. mTOR inhibitors blunt the p53 response to nucleolar stress by regulating RPL11 and MDM2 levels. Cancer Biol Ther. 2014; 15:1499-1514.

53. Dong Z, Tan R, Cao J, Yang Y, Kong C, Du J, Zhu S, Zhang Y, Lu J, Huang B, Liu S. Discovery of polyoxometalatebased HDAC inhibitors with profound anticancer activity in vitro and in vivo. Eur J Med Chem. 2011; 46:2477-2484. 